\title{
Quem Fala do quê nas Notícias de Saúde do Público em 2009: Uma Análise Crítica
}

\author{
BRUNO TOMÉ \\ Universidade do Minho - Portugal - bmltspf@hotmail.com \\ Licenciado em Ciências da Comunicação pela Universidade do Minho, \\ área de especialização em Informação e Jornalismo. Mestrando em Ciências \\ da Comunicação pela Universidade do Minho, área de especialização em \\ Informação e Jornalismo, sub-área de investigação em Ciências Sociais \\ FELISBELA LOPES \\ Universidade do Minho - Portugal - felisbela@ics.uminho.pt \\ Doutora em Informação Televisiva. Professora Associada do Departamento \\ de Ciências da Comunicação da Universidade do Minho. Investigadora \\ principal do projecto 'A Doença em Notícia', financiado pela Fundação \\ para a Ciência e Tecnologia, PTDC/CCI-COM/103886/2008.
}

\begin{abstract}
Resumo
A ciência e a saúde ocupam um lugar de destaque no contexto da cobertura mediática, levando os meios de comunicação social a apresentar diariamente um vasto leque de notícias desse âmbito. Inúmeras vozes e opiniões são escritas e expressas nos vários meios de comunicação social, lançando para as audiências visões e experiências sobre as duas temáticas. Este artigo propõe-se a analisar, de um ponto de vista crítico, que tipo de vozes e assuntos são marcantes nas notícias sobre saúde no Público, um jornal de referência no contexto nacional.
\end{abstract}

\section{Palavras-chave}

Saúde; Comunicação Da Saúde; Jornalismo De Saúde.

\section{Abstract}

Science and health occupy a prominent place within the scope of media coverage, which leading the media to present regularly a wide range of related issues. Numerous voices and opinions are written and expressed in different media, pitching various views and experiences on the two themes to a wide audience. This article proposes to critically examine the kinds of voices and issues related to health that are most prominent in Público, a nationally distributed newspaper with a wide readership.

\section{Keywords}

Health; Health Communication; Health Journalism. 
importância da saúde e da ciência reflete-se na criação de espaços,
programas ou secções específicas dedicadas às duas temáticas pelos meios de
comunicação em geral. Na imprensa generalista, é frequente a existência de
secções dedicadas à ciência e à saúde, muitas vezes alargadas por suplementos: o Diário de Notícias, jornal de referência em Portugal, não descura a existência da secção Ciência. Na televisão e na rádio, nomeadamente nos canais do serviço público, é também dado um destaque substancial às duas temáticas. Na RTP1, Maria Elisa apresenta Serviço de Saúde, programa de periodicidade semanal e na Antena1, Medicina e Saúde, de Mendes Callais e Al Ciência de Clara Pinto Correia, Horácio Periquito e Máximo Ferreira colocam os ouvintes da rádio pública a par das novidades relacionadas com a ciência e a saúde.

À semelhança do que aconteceu com as teorias da comunicação de massa, a comunicação da ciência começou também por ser encarada como um processo exclusivamente unidirecional (Logan, 2001). No modelo tradicional da ciência como comunicação de massa, os especialistas limitavam-se a transmitir os avanços científicos ou as novidades sobre determinada doença, muitas vezes de uma forma excessivamente técnica, para uma audiência pouco interessada e preparada para tal. Tentava-se dar à comunicação pública da ciência um caráter pedagógico, mas que era pouco interessado na efetiva captação da mensagem pelo público. No modelo interativo, adota-se uma perspetiva multidirecional. Dá-se prioridade à interação entre os cidadãos, cientistas, políticos, governo e jornalistas. Mais importante do que informar as pessoas será cativar-lhes o interesse pelas questões relativas à ciência e à saúde, criando uma espécie de conversa informal, uma experiência partilhada (Yankelovich apud Logan, 2001). Apesar de uma maior participação no universo científico (a perspectiva do especialista já não é única e dogmática e as vozes dos cidadãos também chegam à esfera pública), os meios de comunicação mantêm-se como os principais mediadores entre as duas partes. Por isso, é fundamental que os jornalistas e os media em geral assumam uma atitude responsável no tratamento das questões relativas aos campos da ciência e da saúde.

Para haver informação e produção noticiosa, torna-se preponderante o recurso às fontes. Será precisamente na relação entre os jornalistas e as fontes na cobertura e divulgação científica que irei atentar neste momento.

Do latim "fons, fontis", ou seja, nascente, fonte, água, origem, a palavra "fonte" parece significar muito mais do que uma primeira leitura possa indiciar. Sendo Fonte o Deus 
das nascentes, e relacionando a palavra com o tema em estudo - a relação das fontes com os jornalistas -, facilmente chegamos à definição de origem, causa, princípio. Porque, na maioria dos casos, as fontes de informação a que os jornalistas acedem não são mais do que a origem de determinado acontecimento que merece ser noticiado, ou então alguém que nos poderá dar a sua perspetiva sobre a causa de determinada ocorrência. No entanto, a relação entre os jornalistas e as fontes não se processa de uma forma simplista. A relação entre os jornalistas e as fontes é bastante complexa em todas as áreas da sociedade e a ciência e a saúde não fogem à regra.

Tanto no campo da ciência e da saúde, como em todos os outros, as fontes e os jornalistas adotam uma série de estratégias para se influenciarem mutuamente. Se, por um lado, as fontes tentam usar os media para condicionar uma grande variedade de debates, agendas e audiências (Miller et al: 1998), os meios de comunicação, através da sua agenda e assuntos que colocam em debate, também podem alterar o discurso e o modo de atuar das primeiras. Se para Herbert J.Gans a relação entre os media e as fontes de informação se limita a uma "dança", onde as fontes tomam a liderança, Anthony Giddens admite, na sua Teoria da Estruturação, que os media são estruturas estruturadas pela sociedade, mas também estruturas estruturantes da sociedade. Se as fontes podem iludir os meios de comunicação, desviando a sua atenção do que realmente lhes poderá interessar, os media também têm o poder de, através das suas ações, condicionar e colocar pressão sobre poderosos atores governamentais. Os meios de comunicação desempenham também um importante papel no relacionamento entre a ciência e a política, podendo contribuir para mudanças de posição de ambas as partes (Wilson et al apud Hodgetts et al, 2008). Seja como for, a relação entre os jornalistas e as fontes é fundamental no tratamento de qualquer questão sobre ciência ou saúde e quantas mais posições (fontes) existirem numa notícia, mais rica ela será (Hodgetts et al, 2008).

No entanto, cumprir tal objetivo nem sempre é fácil. No campo da ciência e da saúde o acesso a fontes diversificadas pode tornar-se um obstáculo. As fontes oficiais são normalmente bastante acessíveis, tomando muitas vezes a iniciativa de contatar os jornalistas para noticiar determinado facto (Hodgetts et al, 2008). Este caráter proactivo não carateriza na maior parte das vezes as fontes especializadas, que se mostram mais resistentes em colaborar. Para tal, torna-se fundamental que o jornalista procure estabelecer relações de confiança com fontes desse tipo. As fontes não-oficiais, como os cidadãos comuns, revelam-se muitas vezes indisponíveis, pois não se pretendem expor. Nesses casos, o recurso ao anonimato é a solução mais usada para resolver o problema. 
Para melhor entender esta relação entre jornalistas e fontes de informação na área da saúde, estudámos todos os artigos noticiosos publicados ao longo de um ano num jornal nacional de referência. O título escolhido foi o Público e o período temporal, o ano de 2009 (excluímos do nosso trabalho os suplementos e a revista). A nossa pergunta de partida para o estudo foi: "Quem fala do quê nas notícias de saúde do Público em 2009?”, tendo aqui uma atenção particular às fontes aí citadas. Com um total de 583 notícias e através de uma metodologia de natureza quantitativa, procurámos perceber quem se constituía como fonte de informação, integrando na análise sete variáveis: presença/ausência de referência às fontes; número de fontes citadas; lugar geográfico onde se situa a fonte; género; identificação; estatuto; e especialidade médica.

Sabendo que as fontes são fundamentais para a existência de um jornalismo sério e rigoroso, será relevante a sua identificação e estudo para uma correta perceção das vozes que intervieram ao longo de 2009 nas notícias de saúde do jornal Público.

\section{Reflexões de Enquadramento}

Uma vez que o objetivo do trabalho é analisar as fontes citadas nas notícias sobre saúde do jornal Público durante o ano de 2009, será obrigatório perceber o seu lugar no complexo campo da Comunicação na Saúde, nomeadamente no sub-campo do jornalismo de saúde.

A relação entre os jornalistas e as fontes é também fulcral para uma mais alargada perceção do nosso objeto de trabalho. Por isso, procurámos, ao longo deste enquadramento, tratar quatro tópicos: jornalistas e a relação com o poder dominante; jornalistas e a relação com fontes especializadas; ausência de perspetivas alternativas; fontes identificadas e anónimas. $\mathrm{Na}$ parte empírica, procuraremos perceber se as teses referidas neste enquadramento teórico reiteram ou contrariam os dados que resultam do nosso estudo.

\section{Comunicação na Saúde}

A Comunicação na Saúde é uma área de investigação que surgiu na primeira metade da década de 80. Inserida no âmbito das Ciências da Comunicação, teve como nomes de referência Kreps, Thornton, Sharf e Northouse. Na perspetiva de Lopes et al (2010), a Comunicação na Saúde é uma das áreas em que convergem as Ciências da Comunicação e a Saúde Pública, dando-se particular destaque à influência da comunicação humana mediada na prestação e promoção de cuidados de saúde à população. No campo da Comunicação na 
Saúde, cabem, por exemplo, as campanhas de ensino e da prática da medicina e o processo de divulgação científica, etc. (Bueno, 2006).

Neste quadro, será pertinente identificar algumas falhas. Wilson da Costa Bueno (2006), num artigo em que realiza uma revisão crítica desta área, identifica seis problemas que poderão baralhar a perceção das audiências em relação a assuntos ligados à prática da comunicação na saúde.

Em primeiro lugar, a divulgação científica carateriza-se pela fragmentação. Os cidadãos são expostos a um sem número de notícias que funcionam como "peças de um quebra-cabeças", mas, se fossem noticiadas todas juntas, perderiam o seu sentido. Isto acontece porque os media reagem a "espasmos de divulgação". Quando dão a conhecer um tema, fazem-no através de uma overdose noticiosa, esquecendo-o por vezes de um dia para o outro. Ao problema da fragmentação, soma-se o exagerado foco na doença e, por vezes, a visão preconceituosa das terapias alternativas. Na primeira, os meios de comunicação social centram-se em noticiar apenas a doença, não evidenciando esforços ao nível da prevenção. $\mathrm{Na}$ segunda, assiste-se a uma marginalização das terapias não-tradicionais, como é o caso da acupuntura. Para tal, contribui a pressão das entidades ligadas ao ramo da medicina tradicional, muitas vezes fontes de confiança dos meios de comunicação. O quarto problema apontado por Wilson da Costa Bueno é a tendência que os media têm para transformar as notícias sobre saúde num espetáculo. Quando o tema é a saúde, os jornalistas tendem a produzir manchetes espetaculares, que prometem tratamentos milagrosos. Além da criação de um clima de total desinformação, estes discursos podem levar a um consumo inconsequente de medicamentos e atenuar a elevada importância do caráter preventivo. Por último, sublinham-se o mito da técnica omnipotente e a legitimação do discurso de competência. No primeiro caso, é dado à medicina um caráter omnipotente e milagroso, criando-se a ideia de que certos tratamentos são capazes de resolver todos os problemas. No segundo caso, e apesar de se saber que a maioria das pessoas não domina a linguagem médica, tende-se a circunscrever as discussões aos especialistas, que falam numa linguagem completamente hermética, quando esses temas fazem parte do interesse público. Isto não deveria acontecer, porque a ciência e a saúde são parte integrante da esfera pública e a participação do cidadão na discussão das mesmas teria que ser acessível a todos.

\section{Jornalistas e a Relação com o Poder Dominante}

A relação entre os jornalistas e o poder dominante nem sempre assume contornos pacíficos. Reveste-se de inúmeras incompatibilidades e conflitos de interesses, com ambos os 
lados a tentar assumir o controlo das situações. No entanto, jornalistas e poder dominante podem cooperar para o alcance de um objetivo comum, como a divulgação de iniciativas, que visem a prevenção e informação das pessoas relativamente a determinado assunto. Se, por um lado, os media são atores importantes nos processos políticos, desde as instituições centrais do Estado aos mais pequenos grupos sociais, também são passíveis de ser usados e manipulados como tubos de ensaio para captar a opinião geral sobre determinado tema (Miller et al, 1998).

É nos órgãos do poder dominante que se encontram as fontes oficiais, fontes de informação com um elevado nível de credibilidade e precisão discursiva. Por isso, tanto na área da ciência e da saúde, como em qualquer outra, ignorar este tipo de fontes poderia ser um erro crasso para qualquer meio de comunicação jornalístico.

A proactividade é um dos fatores que caraterizam as fontes oriundas do poder dominante; estas fontes tomam a iniciativa de transmitir a informação aos jornalistas (através de press-releases, e-mails ou conferências de imprensa), o que gera um grande volume noticioso. No entanto, os jornalistas terão de estar muito atentos a essa proactividade das fontes oficiais, pois poderá ser nada mais do que um "presente envenenado". Hodgetts (2008) toca precisamente neste aspeto, ao chamar a atenção para a criação de acontecimentos da parte das fontes oficiais. As conferências de imprensa marcadas por essas fontes poderão constituir uma maneira muito fácil de disponibilizar informação sobre determinado assunto, mas também uma tentativa de manipulação da agenda dos meios de comunicação social, afastando a atenção daquilo que realmente lhes poderá interessar e fazer parte do interesse público.

Assim, e não descurando a grande importância que as fontes oficiais constituem para o exercício da atividade jornalística, os jornalistas devem ter aqui uma atitude ativa e atenta, para não ficarem presos a estes estratagemas que os afasta de um jornalismo rigoroso e imparcial. A objetividade deverá constituir uma meta que os jornalistas tentarão sempre alcançar, pois esta é a melhor forma de despolitizar a produção das notícias (Hodgetts et al, 2008).

Hodgetts (2008) alerta ainda para um aspeto que os jornalistas devem tomar em consideração na relação que estabelecem com as fontes oficiais e com qualquer outro tipo de fonte de informação. Sempre que é criada uma relação de confiança entre uma fonte e um jornalista, objetivo que deverá ser procurado, poder-se-á cair na tentação de aceder constantemente à mesma, o que limitará o campo de cobertura e pesquisa dos jornalistas, que poderão assumir a versão dessas fontes de informação como a única e aceite pela generalidade da comunidade científica, ideia que muitas vezes não corresponde à realidade. Deve-se fazer 
um esforço para cumprir a basilar regra do contraditório, em busca de perspetivas alternativas e distintas.

\section{Jornalistas e a Relação com Fontes Especializadas}

A relação entre os jornalistas e as fontes especializadas é também fundamental para o exercício da sua atividade, ainda mais na área da ciência e da saúde. Não nos podemos esquecer que é no lote das fontes especializadas que se concentram médicos, cientistas e grande parte dos profissionais que constituem a vanguarda do conhecimento científico. No entanto, tal como acontece com as fontes oficiais, as fontes especializadas também procuram usar os media para atingir determinados fins. É uma realidade o facto de que um grande número de fontes especializadas fazem muitas vezes parte de organizações privadas com fins lucrativos, que pretendem crescer e ver-se distinguidas na esfera pública. Miller (1998) alerta precisamente para este facto e afirma que as fontes especializadas podem tentar usar os media para angariar fundos e membros, satisfazer necessidades e expetativas, resolver disputas entre as organizações e influenciar a prática local e/ou nacional das políticas do governo.

Sendo menos proactivas do que as entidades oficiais, as fontes especializadas, principalmente nas áreas da ciência e da medicina, têm uma forte preferência pelas comunicações via e-mail, pedindo, por vezes, que o jornalista as contate somente através dessa plataforma (Pavlik, 2004). Isto traz vantagens - o jornalista poderá obter informações credíveis, especializadas e com rigor técnico e científico sem se levantar da sua secretária -, mas também inconvenientes, - perde-se o contato frente-a-frente, estratégia que deve ser sempre adotada como método de trabalho preferencial de um profissional do jornalismo. Com o desenvolvimento da Internet, os jornalistas "aproveitam" cada vez mais outras plataformas para encontrarem informações sobre determinado assunto. As fontes especializadas estão, por vezes, integradas em blogues ou sites que apresentam estudos recentes sobre matérias com interesse público, que podem ser selecionadas e editadas pelos jornalistas (Pavlik, 2004). Uma vez que essas plataformas são mantidas por especialistas e consultadas essencialmente por profissionais ligados a áreas científicas, o uso de linguagem técnica é frequente. Por isso, o jornalista deverá ter alguma especialização nessas matérias para transmitir a informação de forma percetível para o cidadão comum, necessidade que nem sempre se verifica. 


\section{Ausência de Perspetivas Alternativas}

Ao percorrermos os artigos noticiosos que falam de saúde, constata-se frequentemente que as fontes citadas se circunscrevem a um grupo restrito. Quer isto dizer que há uma imensa maioria que não é ouvida. A este nível, temos de recorrer à teoria da espiral do silêncio de Elisabeth Noelle-Neumann (1995) para perceber o que tal tendência significa. Segundo Noelle-Neumann, os meios de comunicação funcionam numa espiral, centrando-se nas opiniões consideradas dominantes, deixando de lado, no silêncio, todos aqueles que não têm acesso à esfera mediática. Um estudo recente sobre a atuação dos media portugueses durante a pandemia da Gripe A, feito por Lopes, Ruão e Marinho (2010) debruçou-se precisamente sobre este facto. $\mathrm{Na}$ perspectiva das investigadoras, durante a pandemia da Gripe A houve uma tendência para se ouvirem sempre as mesmas pessoas, na esmagadora maioria fontes oficiais e fontes especializadas. A supremacia destas fontes de informação sobre as restantes inviabilizou a participação pública de outros testemunhos. Por exemplo: profissionais importantes como enfermeiros e/ou médicos desligados de qualquer cargo e pacientes ou cidadãos comuns que passaram ou temiam passar pela experiência da doença.

Esta tendência vem atestar uma das falhas identificadas na Comunicação da Saúde por Wilson da Costa Bueno (2006), mais precisamente a legitimação do discurso de competência, ou seja, o momento em que se cria uma espécie de barreira entre aqueles que dominam as questões técnicas e científicas e os que estão na margem dessas áreas. Como já foi referido anteriormente, esta não deve ser a opção, pois as questões relativas à saúde e à ciência são do interesse público e cada cidadão, independentemente das suas competências, deverá ter a possibilidade de participar na discussão pública dessas temáticas, desde que a sua opinião/posição tenha relevância.

Além disso, Hodgetts (2008) afirma que os meios de comunicação com maior expressão têm maior dificuldade em contatar fontes não-oficiais, como o cidadão comum, principalmente no que toca a assuntos sensíveis, pois muitos indivíduos não se querem expor. Já os media de menor expressão têm maior facilidade neste aspeto, pois o que for noticiado por eles não terá, em princípio, o mesmo alcance que as notícias publicadas pelas instituições mediáticas com maior importância. Por vezes, a solução é o anonimato, estratégia que deverá ser usada com bastante cautela e sobre a qual me debruçarei a seguir. 


\section{Fontes Identificadas e Anónimas}

Em assuntos relacionados com a saúde, principalmente os mais sensíveis, é perfeitamente compreensível que uma fonte exija o anonimato para partilhar o seu testemunho com o jornalista. O direito à imagem é parte integrante do Código Civil português e todos aqueles que não forem figuras públicas e não se quiserem expor na esfera social têm esse direito. Mas surge aqui uma questão: uma peça jornalística onde o jornalista diz aos seus leitores que a história que lhes transmite é verdadeira, sem nunca identificar o seu protagonista, é ou não credível?

Quando isto acontece, só há uma solução: a confiança dos leitores no meio de comunicação social em causa. A história poderá ser do interesse público e não faria sentido ignorá-la apenas para não utilizar a estratégia do anonimato. Mas isso deverá ser feito a título muito excecional e nunca como prática corrente. Quando isso acontece, a confiança entre os media e os seus leitores não irá colocar em causa a informação publicada, mantendo a credibilidade desse meio de comunicação (Altares, 2004). O anonimato deverá ser sempre encarado como uma via de recurso. Segundo Pavlik (2004), cabe aos jornalistas criarem uma audiência interessada no que é escrito, caso contrário não fazia sentido escrever nada. Quando este esforço é feito, o anonimato não deverá ser encarado como um fator desvalorizador da qualidade jornalística, mas apenas como uma necessidade de exceção.

\section{Metodologia}

Esta investigação pretende perceber quais são e de que falam as fontes de informação citadas em artigos noticiosos sobre saúde no jornal Público durante o ano de 2009. O seu eixo assentou na análise dessas fontes, feita a partir de sete variáveis: presença/ausência de referência às fontes; número de fontes citadas; lugar geográfico onde se situa a fonte; género; identificação; estatuto; e especialidade médica. As variáveis foram tratadas através de uma metodologia de natureza quantitativa (SPSS). Este é um estudo de mapeamento e de vocação extensiva, pelo que se privilegiou a análise quantitativa dos dados, centrada na estatística descritiva univariada. Estas opções assentam no propósito da pesquisa global que é o de fazer um levantamento de regularidades, não tendo havido lugar à formulação explícita de hipóteses ou à consequente medição da associação entre variáveis.

O jornal escolhido foi o Público, diário de referência nacional e o número de artigos noticiosos analisados totalizou 583 textos. Não se pretendeu analisar nenhum outro tipo de 
meio informativo (televisão, rádio, online), por uma questão de conveniência, pois os recursos disponíveis foram reaproveitados de alguns estudos da mesma área.

\section{Quem fala do quê nas noticias de saúde do Público em 2009. Apresentação de resultados}

Durante o ano de 2009, uma parte esmagadora dos textos jornalísticos publicados pelo Público recorreu a fontes de informação. Dos 583 artigos analisados, apenas oito não possuíam qualquer fonte, ou seja, $98,6 \%$ dos textos tinham a presença de, pelo menos, um interlocutor. Em relação ao número de fontes citadas, mais de metade dos textos citam duas e quatro fontes de informação, com 29,1\% e 29,3\%, respetivamente. Estes dados parecem indicar, à primeira vista, uma assinalável pluralidade de vozes e perspetivas. Mas isso nem sempre acontece. Com a análise dos dados relativos ao estatuto das fontes que intervieram nas notícias de saúde do Público, percebe-se desde logo que há uma forte tendência para uma concentração em determinados setores da sociedade. Lopes, Ruão e Marinho (2010) alertaram precisamente para este facto quando estudaram as fontes citadas nos artigos sobre a Gripe A, afirmando que haveria ali uma espécie de "confraria das fontes" que produzia um discurso dominante sobre o que era dito acerca dessa epidemia. Se, por um lado, há uma média aceitável de fontes por notícia, por outro também se observa uma tendência para a sua repetição. Num total de 1550 fontes de informação, o conjunto de fontes oficiais e fontes de especialistas institucionalizados (ou seja de pessoas do campo da saúde detentoras de cargos) traduz-se em mais de metade da amostra. Não nos podemos esquecer que, durante o ano de 2009, assistimos ao surgimento e ao desenvolvimento da Gripe A, factor que certamente teve influência no número de fontes oficiais e de fontes institucionais especializadas (muitas vezes ao serviço das fontes governamentais), mas a análise comprova que esta tendência se alastra a todo o ano. Ao nível das fontes oficiais, recorre-se com frequência à ministra da Saúde, ao diretor da Direção-Geral de Saúde e aos secretários de Estado da Saúde. Nas fontes institucionais especializadas, é comum recorrer-se a médicos, a investigadores, a farmacêuticos e a enfermeiros. De destacar ainda a tendência que o jornal Público assumiu de recorrer frequentemente a informações de outras empresas noticiosas ou a sites na Internet. Esta tendência vai de encontro ao que é defendido por Pavlik (2004), que afirma que, com o desenvolvimento da Internet, os jornalistas vão substituindo as estratégias cara-a-cara com o recurso a informações online (blogues, sites). Sublinhe-se ainda o considerável número de fontes documentais, como sejam, notas/comunicados de imprensa; documentos 
especializados; documentos oficiais; ou outros documentos, dentro ou fora do campo da saúde.

Em termos de distribuição geográfica dos textos, é bastante clara a tendência para se recorrer a fontes de âmbito nacional. Mais de metade (54\%) obedece a tal regra, o que também se constitui como reflexo do estatuto das fontes citadas. As fontes oficiais são maioritariamente de natureza nacional (ministra da Saúde, secretários de Estado) e apareceram com mais frequência durante o pico da Gripe A. Em segundo plano, assistimos a um equilíbrio entre fontes oriundas do Norte do país (8.8\%) e de Lisboa e Vale do Tejo (10.7\%). Devido à ocorrência da Gripe A, o ano de 2009 ficou também marcado por um número considerável de fontes provenientes da Europa (10.2\%) e da América do Norte (8.4\%). Estas fontes de informação são comuns na área de saúde, pois grande parte dos estudos e investigações científicas têm a sua origem nestes locais, mas o número cresceu exponencialmente com o aparecimento da Gripe A. O surto de gripe surgiu no México e as primeiras notícias relatavam o desenvolvimento do vírus nesse país, mas, passado pouco tempo, a noticiabilidade centrou-se nos continentes europeu e norte-americano, locais onde estavam localizadas fontes que poderiam falar à escala global, como a Organização Mundial de Saúde (OMS).

No que toca ao género, as fontes são, sobretudo, do sexo masculino. Embora seja um facto que as mulheres têm cada vez maior peso em todas as áreas da sociedade, os meios de comunicação continuam a preterir o testemunho feminino em relação ao dos homens. Durante 2009, mais de metade das fontes de informação escolhidas pelo Público nos seus artigos sobre saúde foram do género masculino. Esta tendência poderá estar diretamente relacionada com o facto de os homens ainda estarem em clara maioria nos cargos mais importantes e, consequentemente, com maior visibilidade social. A percentagem de fontes do sexo feminino teria sido ainda menor, se a ministra da Saúde não se tivesse constituído como uma fonte regular ao longo do ano, em virtude da pandemia da Gripe A, promovendo sucessivas conferências de imprensa. De destacar ainda o considerável número de fontes coletivas, ou seja, o testemunho das classes de profissionais pertencentes ao ramo da saúde, como sejam, os médicos, enfermeiros, ou investigadores.

Durante 2009, a quase totalidade das fontes de informação que figuraram nas notícias de saúde do jornal Público foram identificadas. Notou-se a preocupação dos jornalistas em deixar claro quem era a fonte que estava a prestar declarações. Na grande maioria dos casos, os leitores tiveram à sua disposição o nome e cargo das testemunhas. As fontes nãoidentificadas aparecem em número muito menor. Mas, mesmo nessas situações, foram 
fornecidos dados sobre a instituição que essa pessoa representava. Situações como "fonte do hospital de Santa Maria" ou "fonte do Ministério da Saúde" são exemplos paradigmáticos desta tendência. As fontes anónimas aparecem de forma completamente residual e foram usadas apenas nas situações em que se pretendeu preservar a testemunha. Em muitos casos foi-lhe mesmo atribuído um nome fictício, protegendo, assim, a exposição social dos indivíduos quando era noticiado algum assunto mais sensível ou constrangedor.

Por último, atentemos à especialidade das fontes de informação. Durante 2009, e mais uma vez devido à onda pandémica de Gripe A que assolou o mundo, registra-se um número invulgar de fontes ligadas às especialidades de pneumologia e doenças infeciosas. É comum também o aparecimento de especialistas ligados à oncologia. As doenças cancerígenas são normalmente muito temidas pela população e a Ciência ainda não foi capaz de encontrar uma vacina para o cancro. Por isso, nota-se uma tendência dos jornalistas do Público para noticiarem os avanços na medicina ligados a esta área e situações de pessoas que vão perecendo com esta doença. De destacar ainda o número de especialistas que dão o seu testemunho sem o leitor ter a possibilidade de perceber em concreto qual é a sua especialidade. Como já foi referido, os jornalistas têm o cuidado de identificar a fonte pelo seu nome e cargo, mas muitas vezes deixam a questão da especialidade de parte ou pouco clara para os leitores.

\section{A supremacia das fontes oficiais/especializadas e a progressiva inclinação pelo jornalismo tecnológico}

Os resultados explicitados e analisados ao longo deste trabalho conduzem-nos a uma conclusão inequívoca: são as fontes oficiais e especializadas organizadas que controlam o discurso mediático sobre saúde. Em situações de risco, como foi o caso da onda pandémica de Gripe A, os media vêem-se obrigados a fazer a dispensável função de "pé de microfone" (Lopes, Ruão e Marinho, 2010), reproduzindo o discurso das fontes oficiais e das fontes especializadas ao serviço das instâncias governamentais. Quando se pretende a visão sobre um qualquer assunto ligado à saúde (uma doença, o desenvolvimento de uma vacina), dá-se uma total primazia aos especialistas dessas áreas, esquecendo o testemunho e a opinião do cidadão comum, por vezes implicado diretamente nessas situações.

Se, como afirma Bueno (2006), a comunicação em saúde deve ser transparente, democrática e de acordo com os interesses da maioria, há que partir rumo à pluralidade de vozes e opiniões, não assumindo nada como certo e refletindo a visão de todos os quadrantes 
da sociedade. Em situações dominadas pela polémica/conflito, há também que respeitar o princípio do contraditório, uma regra básica e indispensável da actividade jornalística, mas também da Ciência, campo que deve recusar qualquer tipo de dogma ou certeza, partindo sempre da premissa de que o erro é eternamente possível de acontecer. Se este objetivo for cumprido, o leitor sertir-se-á certamente mais identificado com o que lê, pois terá contato com visões de pessoas na mesma situação que ele, ou seja, indivíduos que têm uma opinião sobre determinado tema, mas que nunca tiveram a oportunidade de a expressar, pois a sua palavra e contributo são colocados muitas das vezes à margem.

Neste trabalho esboçou-se uma tendência que se vem sentindo tanto no jornalismo de saúde como no jornalismo em geral: a "tecnologização" do trabalho jornalístico. O volume de fontes oriundas de plataformas online é, de facto, expressivo, assistindo-se à seleção de inúmeros conteúdos de blogues e sites. Pavlik (2004) sublinha esta tendência e afirma que as relações fundamentais entre os jornalistas e as fontes e os jornalistas e as suas audiências se estão a alterar devido ao desenvolvimento tecnológico. Perde-se o importante contato cara-acara, mas ganha-se um imediatismo que pode ser um fator valioso no jornalismo actual. $\mathrm{O} e$ mail, por exemplo, possibilita o acesso a especialistas que se localizam longe da redação e permite a comunicação de forma escrita, muitas vezes mais clara do que a expressão oral. Os blogues e sites poderão conter um tipo de informação mais pessoal e íntima, que, depois de devidamente editada, poderá fornecer perspetivas mais sinceras e com uma linguagem menos técnica. Além disso, abre-se cada vez mais a possibilidade a uma interação entre o leitor e os jornalistas, indicando-se plataformas online que poderão ser consultadas para completar a informação transmitida nas páginas do jornal. 


\section{Referências Bibliográficas}

ALTARES, G. Fuentes, secretos y manipulaciones. Cuadernos de Periodistas, v.2, n.9, 1-18, 2004.

BUENO, W. Comunicação para a saúde: uma revisão critica. Disponível em:

$<$ http://www.comunicasaude.com.br/comunicasaude/artigos/jornalismo_saude/artigo12.php>. Acesso em: 23 de Julho de 2010.

HODGETTS, D. et al Constructing health news: possibilities for a civic-oriented journalism. Health, v.12, n.1, 43-66, 2008.

LOGAN, A. R. Science Mass Communication: It's Conceptual History. Science Mass Communication, Sage, v.23, n.2, 2001.

LOPES, F.; RUÃO, T.; MARINHO, S. (2010). “Gripe A na imprensa portuguesa: uma doença em notícia através de uma organizada estratégia de comunicação. Observatório (OBS*) Journal, v.4, n.4, 2010.

MILLER, D.; WILLIAMS, K. Sourcing AIDS News. In DAVID MILLER et al., The circuit of Mass

Communication: media strategies, representation and audience reception. Sage: Londres, 1998. p.123 -146.

NOELLE-NEUMANN, E. La espiral del silencio: Una teoria de la opinión pública. In FERRY, JEAN-MARC et al. El Nuevo Espacio Publico. Barcelona: Gedisa Editorial, 1995

PAVLIK, V. J. A Sea-Change in Journalism: Convergence, Journalists, their Audiences and Sources. Sage:

Londres, 2004

Este artigo e todo o conteúdo da Estudos em Jornalismo e Mídia estão disponíveis em http://www.periodicos.ufsc.br/index.php/jornalismo/index

Estudos em Jornalismo e Mídia está sob a Licença Creative Commons. 